This is the publisher's pdf version of: Zachhuber, J. (2005). 'Friedrich Schleiermacher und Albrecht Ritschl. Kontinuitäten und Diskontinuitäten in der Theologie des 19. Jahrhunderts', Zeitschrift für Neuere Theologiegeschichte/Journal for the History of Modern Theology, 12(1), 16-46. The final publication is available at www. degruyter.com. See: http://dx.doi.org/10.1515/znth.2005.12.1.16

\title{
Friedrich Schleiermacher und Albrecht Ritschl. Kontinuitäten und Diskontinuitäten in der Theologie des 19. Jahrhunderts
}

\author{
Johannes Zachhuber
}

Derjenige, dessen Bekanntschaft mit der Theologie des 19. Jh. mit der Lektüre der einschlägigen Arbeiten Karl Barths begonnen hat, wird sich vielleicht über folgende Beobachtung wundern. Im Jahre 1928, ein Jahr nach dem Erscheinen von Barths Christlicher Dogmatik, schreibt Martin Rade, Herausgeber der liberalen Christlichen Welt, an seinen Freund und Lehrer Adolf von Harnack:

Wer hätte gedacht, daß wir noch einmal so für Schleierm[acher] eintreten würden ${ }^{1}$.

Die Bemerkung erscheint als ein gleichsam dahingeworfenes Postscriptum am Ende des Briefes. Ihr Verständnis und ihre Plausibilität setzt der Verfasser offenbar voraus.

Darin sollte er sich nicht getäuscht haben. Harnacks Reaktion, ähnlich kurz, zeigt volles Verständnis des von Rade anscheinend Intendierten:

Daß Du und wir dabei [im Vorangehenden war von Rades publizistischen Bemühungen um die „Bewahrung und Erhaltung unser(es) so viel größere(n) und freu-

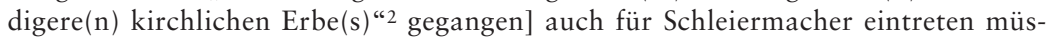
sen, ist freilich unerwartet $\mathrm{u}$ [nd] vielleicht eine Strafe für an ihm verübtes Unrecht; aber die von Ritschl an ihm geübte Kritik bleibt in der Hauptsache zu Recht bestehen $^{3}$.

Harnacks Antwort macht explizit, was sich ansonsten nur hätte erschließen lassen: Dass nämlich die gemeinsame Verwunderung der beiden

\footnotetext{
1 Johanna Jantsch (Hg.), Der Briefwechsel zwischen Adolf von Harnack und Martin Rade. Theologie auf dem öffentlichen Markt, Berlin/New York (De Gruyter) 1996, 836. Hervorhebungen so im Original.

2 Jantsch, Briefwechsel (Anm. 1), 837. Zum historischen Hintergrund sei auf die von beiden mitunterzeichnete Eingabe Hermann Mulerts an die Preußische Akademie der Wissenschaften vom Sommer 1927 verwiesen, die die Erarbeitung einer kritischen Schleiermacherausgabe anregt. Der Text ist abgedruckt in: H.-J. Birkner, Die Kritische Schleiermacher-Ausgabe zusammen mit ihren Vorläufern vorgestellt (1989), in: ders., Schleiermacher-Studien, eingeleitet und hg. v. H. Fischer, Berlin/New York (De Gruyter) 1996, 309-335, hier: 332-335.

3 Jantsch, Briefwechsel (Anm. 1), 837.
}

ZNThG/JHMTh, 12. Bd., S. 16-46

(C) Walter de Gruyter 2005 
Theologen ihre Ursache hat in der kritischen Haltung Albrecht Ritschls und seiner Schule gegenüber Schleiermacher. Auch noch im Jahr 1928 ist Harnack offensichtlich davon überzeugt, dass diese Kritik in ihren Grundzügen berechtigt war.

Nun ist dieser Sachverhalt an sich keine besonders neue und beachtenswerte Entdeckung. Diese kritische Grundhaltung bei Ritschl im Besonderen ist vielmehr offensichtlich, sobald man sich mit seinen Schriften beschäftigt; dass das Selbstbewusstsein Ritschls und seiner Schule wie auch ihre polemische Taktik andererseits nicht zum Mindesten darauf beruhte, ihre Gegner (die bekanntlich von den konfessionellen Lutheranern zu den Liberalen reichten) allesamt unter der Rubrik „auf der Schleiermacherlinie“ zu subsumieren, wird ebenfalls deutlich, sobald man einen Blick auf die einschlägige Polemik der Zeit wirft ${ }^{4}$.

Und doch lehrt selbst ein flüchtiger Blick in Ritschls Schriften, dass sein Verhältnis zu Schleiermacher sich nicht in Ablehnung erschöpft. Wenn man sich nämlich, durch die Polemik neugierig gemacht, auf die Suche begibt nach einer theologischen, Generalabrechnung' Ritschls mit Schleiermacher - ähnlich derjenigen, die Barth mit dem „Kirchenvater des 19. Jahrhunderts" gehalten hat - dann wird man enttäuscht. Vielmehr stellt sich ein ambivalenter Eindruck ein. Wo immer Ritschl sich mit Schleiermacher theologisch auseinandersetzt, verschwindet der polemische Ton (oder wird zum mindesten deutlich zurückgenommen) und macht einer mehr oder weniger sachlichen Analyse Platz, in der sich Kritik und Zustimmung durchaus die Waage halten.

Angesichts dessen ergibt sich die Frage, wie genau denn nun das Verhältnis Ritschls zu seinem großen Vorgänger zu bestimmen sei. Eine Antwort auf diese Frage, wie sie im Folgenden zu geben versucht wird ${ }^{5}$, weist

4 Vgl. besonders: Albrecht Ritschl, Schleiermachers Reden über die Religion und ihre Nachwirkungen auf die evangelische Kirche Deutschlands, Bonn (Marcus) 1874, $59 \mathrm{ff}$. Im Folgenden zitiert als SR.

5 Ritschls Auseinandersetzung mit Schleiermacher hat über pauschale Zusammenfassungen hinaus weniger Beachtung in der Sekundärliteratur gefunden als man erwarten würde. Die folgenden Arbeiten sind auch dort benutzt worden, wo nicht ausdrücklich auf sie verwiesen wird: James K. Graby, The Problem of Ritschl's Relationship to Schleiermacher, in: Scottish Journal of Theology 19 (1966), 257-268; Gösta Hök, Die elliptische Theologie Albrecht Ritschls nach Ursprung und innerem Zusammenhang, UUA 1942,3, Uppsala/Leipzig (Harassowitz) 1942; Dietrich Korsch, Glaubensgewißheit und Selbstbewußtsein. Vier systematische Variationen über Gesetz und Evangelium, Beiträge zur historischen Theologie 76, Tübingen (Mohr) 1989, bes. 8-73; Eilert Herms, Religion, Wissen, Handeln bei Schleiermacher und in der Schleiermacher-Rezeption, in: Ulrich Barth/Claus-Dieter Osthövener (Hg.), 200 Jahre „Reden über die Religion“. Akten des 1. Internationalen Kongresses der Schleiermacher-Gesellschaft. Halle 14.-17. März 1999, Schleiermacher Archiv 19, Berlin/New York (De Gruyter) 2000, 142-166; Arnulf von Scheliha, Albrecht Ritschls Deutung von Friedrich Schleiermachers Reden, Über die Religion', ebd., 728-747; Christoph Senft, Wahrheit und Wahrhaftigkeit, Beiträge zur 
dabei über das spezielle Interesse an Ritschl und seiner historischen Verortung hinaus auf das Gesamtverständnis der theologischen Entwicklung im 19. Jahrhundert. Die Barthsche These von einer wesentlichen Kontinuität dieser Entwicklung war in gewisser Weise eine Antwort auf die von manchen Ritschlianern vertretene These einer wesentlichen Diskontinuität - in beiden Fällen offensichtlich nicht ohne ein Interesse an Selbstprofilierung ${ }^{6}$. Die vorliegende Untersuchung wird jedoch zeigen, dass es mit einer einfachen Alternative hier nicht getan ist, dass Elemente des Weiterwirkens Schleiermachers eng verzahnt sind mit solchen fundamental anderer Grundentscheidungen. Die in dieser Hinsicht anzustellenden Beobachtungen wiederum können nicht ohne Konsequenzen für die heutige theologische Orientierung bleiben, die in vielerlei Hinsicht nach wie vor unter dem Einfluss der Entwicklungen und Verwicklungen des 19. Jahrhunderts steht. Diese Perspektive wird am Ende dieser Untersuchung zumindest angedeutet.

Die im Folgenden vorgelegte Interpretation orientiert sich eng an Ritschls eigenen Texten. Daraus ergibt sich die Gliederung in:

1. Ritschls Polemik;

2. Differenzierte Anerkennung und

3. Die Kritik.

Ein kurzes Fazit (4) zieht abschließend die Konsequenzen.

\section{Polemik}

Aus Ritschls Feder gibt es eine ganze Reihe expliziter Absagen an Buchstaben und Geist Schleiermacherschen Denkens. Die bekanntesten finden sich in der von seinem Sohn, Otto Ritschl, herausgegebenen Biographie. So äußert sich Ritschl brieflich im Jahr 1873: „Ich weiß nur, daß in dogmaticis ich keine Spur von seiner Methode und seinen Zielen in mir finde. “7 Anderswo schreibt er lakonisch: Schleiermachers „Bewunderung muß aufhören!" 8

Will man solche Polemik richtig einschätzen, dann bietet sich als Ausgangspunkt diejenige Schrift an, in der Ritschl sich dem Anschein

historischen Theologie 22, Tübingen (Mohr) 1956, bes. 130-134; Johannes Weinhardt, Wilhelm Herrmanns Stellung in der Ritschlschen Schule, Beiträge zur historischen Theologie 97, Tübingen (Mohr) 1996, bes. 140-146.

6 Darauf hat Martin Rade bereits 1925 hingewiesen: Vgl. Christian Nottmeier, Adolf von Harnack und die deutsche Politik 1890-1930. Eine biografische Studie zum Verhältnis von Protestantismus, Wissenschaft und Politik, Beiträge zur historischen Theologie 124, Tübingen (Mohr) 2004, 85.

7 Otto Ritschl, Albrecht Ritschls Leben, 2 Bd., Freiburg (Mohr) 1892-96, II, 149 (aus einem Brief an Ludwig Diestel vom 20. 3. 1873).

8 O. Ritschl, Leben (Anm. 7) II, 83. 
nach unmittelbar mit seinem großen Vorgänger auseinandersetzt: Schleiermachers Reden über die Religion und ibre Auswirkungen auf die evangelische Kirche Deutschlands von 1874.

Tatsächlich zerfällt dieses Buch in zwei Teile, die ziemlich genau den zwei Hälften des Titels entsprechen. Nur der erste (Kapitel 1-8) handelt von Schleiermachers Reden selbst. Er bietet eine in vieler Hinsicht interessante und stimulierende, kritische, aber auch anerkennende Auslegung ihrer Hauptgedanken. Darauf wird noch zurückzukommen sein.

Im zweiten Teil dagegen (Kapitel 9-13) geht es dem Verfasser darum, in z.T. scharfer Polemik die wesentlich negativen Auswirkungen der Schrift Schleiermachers darzustellen. Hier möchte Ritschl demonstrieren, dass die

Reden über die Religion als das Programm der Verwickelungen zu erkennen sind, welche den Gang der deutschen evangelischen Kirche im 19. Jahrhundert ausfüllen'.

Es geht ihm dabei um den Nachweis, dass sich diese ,programmatische“ Bedeutung der Reden nicht zuletzt an solchen kirchlichen und theologischen Strömungen zeigt, die sich selbst keineswegs als Erben Schleiermachers verstanden, und die auch Schleiermacher selbst nie als legitime Erben hätte akzeptieren können, wie die Erweckung und das konfessionelle Luthertum. Ritschl aber ist in dieser Hinsicht hart:

Auch die Repristination der vollständigen lutherischen Überlieferung [steht ...] keineswegs außer Verhältniß zu dem von Schleiermacher gewiesenen Wege. Daß er selbst dieses Ziel nicht erstrebt hat, dient nicht zur Widerlegung dieser Behauptung; denn die persönliche Absicht der Menschen hängt noch von anderen Bedingungen $\mathrm{ab}$, als von allgemeinen Grundsätzen und deren logischer Folgerichtigkeit ${ }^{10}$.

Dabei darf nicht übersehen werden, dass bereits die Entscheidung Ritschls, als Fluchtpunkt der Untersuchung nicht die Glaubenslehre, sondern die Reden zu wählen, zu diesem Zeitpunkt provokativ sein musste. Wilhelm Dilthey schildert die von ihm selbst noch erlebte Schleiermacherverehrung der 1860er Jahre im Rückblick so:

Es war der Schleiermacher der letzten Zeit [sc. seines Lebens], der Vertreter der Lehre von dem einzigartigen sündlosen Charakter Christi, vom religiösen Gemeindebewusstsein, vom vorbildlichen Charakter des Urchristentums, der hier verehrt wurde. Und in dem vielstimmigen Chor seiner Verehrer waren diese Stimmen weitaus vorherrschend. Die Gegner Schleiermachers erhoben die für diese seine Verehrer verletzende Anklage, die schon zu Schleiermachers Lebzeiten laut geworden war, in den Reden über die Religion herrsche Spinozismus. Wenn von seiner Beziehung zu den Romantikern die Rede war, so sprach man von ihr als von einem Durchgangspunkt zu einer reiferen Entwicklung; an die Luzindenbriefe wurde man nicht gern erinnert ${ }^{11}$.

9 SR (Anm. 4), 107.

10 SR (Anm. 4), 67.

11 Wilhelm Dilthey, Leben Schleiermachers I, hg. Martin Redeker, Berlin (De Gruyter) 31970, 549 (Bruchstücke einer Vorrede Diltheys zur 2. Auflage des 1. Bandes). 
Diltheys Schleiermacherbiographie, die den stärksten Impuls für eine Hinwendung auf die Frühzeit des Theologen lieferte, lag Ritschl 1874 natürlich bereits vor. Ritschls eigenes Buch ist von ihr mit angeregt ${ }^{12}$ und in seinem sachlichen Interesse an den Reden auch ein Beispiel für den Perspektivwechsel der Schleiermacherinterpretation nach $1870^{13}$. Dennoch musste es für das kirchliche und theologische Deutschland doppelt kränkend sein, in seiner Gänze dem Einfluss einer - wie man es sah - romantischen, ästhetisch-pantheistisch inspirierten und - alles in allem - so wenig kirchlichen Schrift zugeschrieben zu werden.

Dabei ist nicht so sehr entscheidend, inwieweit die von Ritschl angestellten Beobachtungen tatsächlich im Einzelnen berechtigt sind ${ }^{14}$. Denn ganz offensichtlich kommt es Ritschl hier nicht primär auf eine korrekte geistesgeschichtliche Ableitung an. Vielmehr ist es sein Ziel, Luthertum und modernen Pietismus durch den Aufweis ihrer Herkunft vom liberalen Schleiermacher zu delegitimieren, andererseits denjenigen pointiert $\mathrm{zu}$ widersprechen, die - wie I. A. Dorner - der Ansicht waren, „der Einfluß Schleiermachers und der von ihm bestimmten Theologie“ sei der „vornehmste Damm gegen eine nachhaltigere Wirkung von Strauß“ gewesen ${ }^{15}$.

Bezeichnend ist daher vor allem auch Ritschls Umgang mit denjenigen, die sich selbst auf Schleiermacher beriefen, den so genannten Vermittlungstheologen. Diesen gegenüber grenzt Ritschl sich ganz klar, ja schroff, ab. Mehrfach weist er explizit auf den inferioren Charakter der Schleiermacher vorgeblich nachfolgenden Richtung hin. So schreibt er von Neander, an dessen „theologischer Persönlichkeit“ vergegenwärtige sich besonders deutlich,

daß die anregende Wirkung Schleiermachers mit einem höchst auffallenden Mangel an genauer wissenschaftlicher Methode zusammentreffen konnte ${ }^{16}$.

12 Vgl. den Hinweis in SR (Anm. 4), 2.

13 Vgl. parallel zu Ritschls eigener Veröffentlichung auch: Richard Adelbert Lipsius, Schleiermachers Reden über die Religion in: Jahrbücher für Protestantische Theologie 1 (1875), 134-184; 269-315. Im Unterschied zu Dilthey und Lipsius legt Ritschl seiner Beschäftigung mit den „Reden“ allerdings nicht deren erste, sondern die dritte Auflage zu Grunde. Vgl. v. Scheliha, Ritschls Deutung (Anm. 5), 728 und O. Ritschl, Leben (Anm. 7); II $247 \mathrm{f}$.

14 Vgl. zur Verbindung von Schleiermacher und v. Hofmann: Wilhelm Herrmann, Christlich-protestantische Dogmatik, in: Paul Hinneberg (Hg.), Die Kultur der Gegenwart. Ihre Entwicklung und ihre Ziele. Teil I, IV. Abt.: Systematische christliche Religion, Leipzig (Teubner) 1906, 21909, 129-180, hier: 151, 153-155; zit. nach.: Peter FischerAppelt (Hg.), Wilhelm Herrmann. Schriften Zur Grundlegung der Theologie, München (Kaiser) 1966/67, 1, 298-361 (Seitenzahlen hier und im Folgenden sind die der 2. Auflage der Originalausgabe); zu Schleiermachers Einfluss auf Strauß während dessen theologischer Entwicklung: Gotthold Müller, Identität und Immanenz. Zur Genese der Theologie von D.F. Strauß, Zürich (EVZ) 1968, 215-222.

15 Isaak August Dorner, Geschichte der Protestantischen Theologie, München (Cotta) $21867,793$.

16 SR (Anm. 4), 65. 
Und an derselben Stelle heißt es verallgemeinernd:

Wenn ich mir die anderen Männer jener Epoche, welche am meisten an Schleiermachers Bedeutung für die Theologie glaubten, aus persönlicher und literarischer Bekanntschaft vergegenwärtige, so fehlte ihnen nichts mehr als die Absicht auf präcises Denken und auf geschlossene Systematik in der Theologie ${ }^{17}$.

Erst ganz am Ende der Schrift kommt Ritschl auf die, eigentlichen' Schleiermacherianer zu sprechen, sagt dort aber über ihren Zusammenhang mit Schleiermacher - eigentlich nichts. Die Beurteilung „dieser Männer, so wie sie im Dienste der kirchengeschichtlichen Kunde ausgeübt werden dürfte" sei vielmehr

deshalb unausführbar, weil diejenigen, welche das geistige Erbe Schleiermachers am directesten vertreten haben mögen, als solche nicht in die Öffentlichkeit getreten sind, ohne welches ein wissenschaftliches Urteil nicht erlaubt ist ${ }^{18}$.

Ritschl beschränkt sich im Folgenden auf eine Diskussion der von den Liberalen im Anschluss an Schleiermacher verfochtenen kirchenpolitischen Forderung nach einer Trennung von Kirche und Staat - also ausdrücklich keinen theologischen Zusammenhang.

In dieselbe Richtung zielt die Argumentation Ritschls in dem wenig früher (1870) in erster Auflage erschienenen ersten Band der Christlichen Lehre von Rechtfertigung und Versöhnung ${ }^{19}$. Die These dort ist grundsätzlich dieselbe wie in der Schleiermacherschrift. Der Zusammenhang zwischen Schleiermacher und seinen selbsternannten Nachfolgern sei nicht so, dass er es erlaube, hier von einer Schule zu reden und folglich sei Schleiermacher nicht „Epoche machende[r] Begründer“ einer besonderen theologischen Entwicklung im 19. Jahrhundert. ${ }^{20}$

17 SR (Anm. 4), 65.

18 SR (Anm. 4), 94.

19 Die christliche Lehre von der Rechtfertigung und Versöhnung, Band 1, Bonn (Marcus) 11870, 465-523 (dem entspricht mit wenigen Änderungen: RuV I², 484-542). Zitiert im Folgenden als RuV mit Bandangabe in römischen Ziffern und hochgestellter Angabe der Auflage. Die vieldiskutierte Frage nach Ritschs theologischer Entwicklung und entsprechend nach nuancierten Unterschieden zwischen den verschiedenen Auflagen seiner Hauptschriften liegt außerhalb dessen, was der vorliegende Beitrag leisten kann. Für die meisten hier zu verhandelnden Fragen, insbesondere für Ritschls Sicht auf Schleiermacher, ist dies Problem allerdings zu vernachlässigen. Vgl. zur Frage etwa: Cajus Fabricius, Die Entwicklung in Albrecht Ritschls Theologie von 1874 bis 1889 nach den verschiedenen Auflagen seiner Hauptwerke dargestellt und beurteilt, Tübingen (Mohr) 1909. Bei der Zitation wird in der Regel auf die jeweils letzte Ausgabe verwiesen.

$20 \mathrm{RuV} \mathrm{I}^{2}$ (Anm. 19), 484. In der Einleitung hatte er angekündigt, „die allgemeinen Stützpunkte, welche die Geschichte der Theologie der Lösung meiner besonderen Aufgabe darbieten müsste, [...] selbständig zu erforschen “, da „man von Allen im Stiche gelassen wird, wenn man klar und deutlich erfahren will, [...] worin eigentlich Schleiermacher's Anspruch beruht, die deutsch-evangelische Theologie dieses Jahrhunderts zu leiten.“ (S. $26 \mathrm{f}$.). 
Warum nun ist Ritschl in scheinbar haarspalterischer Weise daran interessiert, zwischen Schleiermacher und seine Schüler einen Keil zu treiben? Warum will er ihre Berufung auf den Meister nicht akzeptieren? Die Antwort muss wohl lauten: die primäre Absicht ist Polemik gegen die Angehörigen dieser theologischen Gruppe. Ihnen soll der Anspruch, den Geist Schleiermachers zu vertreten und damit einer besonderen theologischen Epoche zur Geltung zu verhelfen, bestritten werden. Diese Kritik wiederum wurzelt in Ritschls generell abschätziger Meinung über diese Theologen und ihre wissenschaftliche Leistung, von denen er, wie die angeführten Zitate belegen, schlicht nichts hält.

Wichtig scheint zweierlei. Erstens: Ein solches Urteil über diejenigen Männer, die um die Mitte des 19. Jahrhunderts Schleiermachers Banner hochhielten, musste natürlich auf Ritschls Schleiermacherbild abfärben. D.h. man darf annehmen, dass Ritschls Schleiermacherkritik, zumindest wo sie pauschal und polemisch erscheint, sicher nicht zuletzt durch seinen Affekt gegen die „Vermittlungstheologie“ zu erklären ist ${ }^{21}$.

Zweitens: dass Ritschl in den zwei untersuchten Schriften aus den 70er Jahren sich so deutlich bemüht, zwischen Schleiermacher und seinen vermeintlichen Schülern zu scheiden, deutet bereits die Möglichkeit an, dass er in seiner Bewertung zwischen beiden einen deutlichen Unterschied machen will. Denn wenn die ,Schleiermacherianer' seiner Zeit, die er ablehnt, gar nicht wirkliche Schleiermacherianer sind, dann folgt aus deren Minderwertigkeit eben nicht zwangsläufig die Minderwertigkeit ihres angeblichen Lehrers.

Dass sich dies nun in der Tat so verhält, dafür gibt es mehrere Hinweise. Zunächst zwei Beispiele aus Ritschls systematischem Hauptwerk Die christliche Lehre von der Rechtfertigung und Versöhnung. Sie finden sich am Anfang des dritten Bandes, in dem die Grundlagen von Ritschls systematischer Theologie entwickelt werden 22 und sind von entsprechend zentraler Bedeutung.

Schleiermacher wird hier das Verdienst zugesprochen, als erster in der neueren Theologie, die Aufgabe einer Bestimmung des Wesens der christlichen Religion richtig ausgesprochen zu haben:

Die Form der systematischen Theologie ist zunächst an den richtigen und vollständigen Begriff von der christlichen Religion geknüpft. [...] Erst mit Hinzuziehung der allgemeinen Religionsgeschichte kann die spezifische Eigentümlichkeit des Christentums ermittelt werden, welche in allen Beziehungen der theologischen Erkenntnis gewahrt werden muß. Dieses Verfahren ist nun erst durch Schleiermacher eingeschlagen worden, und deshalb ist seine Definition der christlichen Religion so bedeutsam auch wenn sie bei genauerem Hinsehen berechtigten Ansprüchen keineswegs entspricht ${ }^{23}$.

21 Vgl. auch O. Ritschl, Leben (Anm. 7), II, 82-84, wo die Kritik an Schleiermacher ständig mit dem Unbehagen an der Vermittlungstheologie verknüpft erscheint.

22 Vgl. RuV III ${ }^{3}$ (Anm. 19), III.

$23 \mathrm{RuV}, \mathrm{III}^{3}$ (Anm. 19), 9; vgl. III' ${ }^{1}, 4$. 
Darüber hinaus wird Schleiermacher ausdrücklich gelobt für seine Profilierung des Begriffs „Reich Gottes“:

Schleiermacher aber ist der Erste, der den richtigen Gedanken von der teleologischen Art des Gottesreiches zur Bestimmung des Begriffs verwendet hat; und dieses Verdienst soll ihm nicht vergessen werden, wenn er auch die Entdeckung nicht mit sicherer Hand zu ergreifen vermocht hat ${ }^{24}$.

An beiden Stellen wird Schleiermacher eine grundsätzliche und für Ritschls eigene Theologie offenbar grundlegende Einsicht zugesprochen. Nicht nur das; es wird ihm darüber hinaus auch attestiert, er sei der erste gewesen, der die entsprechende Einsicht zur Geltung gebracht habe. Wenn man sich dies klarmacht, erübrigt sich schon eine solche Deutung des Sachverhaltes, die auf eine einseitige Absage Ritschls an Schleiermacher hinauslaufen würde25.

Ganz analog findet man Bemerkungen in der Schleiermacherschrift, nach denen Schleiermachers Nachfolger gerade das Wichtige an Schleiermacher übersehen hätten und daher eine durchaus mögliche und denkbare positive Anknüpfung an Schleiermacher von seinen Schülern unterlassen worden $\operatorname{sei}^{26}$.

Dieselbe Tendenz zeigt sich am deutlichsten in einer wiederum hochpolemischen Passage aus Ritschls Kampfschrift Theologie und Metaphysik (1881). Im Zusammenhang seiner Auseinandersetzung mit einem Artikel des Tübingers Hermann Weiß27 geht Ritschl auf den Vorwurf ein, seine Lehren stünden im Widerspruch zu Schleiermacher. Sein Einwand lautet dort:

Es ist aber nicht Schleiermacher, wie er wirklich war, sondern ihre Idee, ihr stumpfes und zurecht gemachtes Erinnerungsbild von der Lehrweise des großen Theologen, welchem sie zugleich alle ihre Intentionen und Verdienste zurechnen. Dieser im Sinne einer schlaffen Vermittlungstheologie idealisierte Schleiermacher wird nun in Scene gesetzt, um die Ansichten der Herren zu decken, die anderswo wurzeln als bei ihm, und die nach einer entgegengesetzten Erkenntnißmethode entworfen sind, als welche er gehandhabt hat ${ }^{28}$.

Im selben Kontext fällt der oft zitierte Satz, nach dem Schleiermacher „,in Hinsicht der Methode" Ritschls Vorgänger gewesen sei29. Dazu gleich mehr.

$24 \mathrm{RuV} \mathrm{III}^{3}$ (Anm. 19), 12.

25 Dies ist offenbar das Fazit von Weinhardt: „So viel aber steht fest: Es gab schon im 19. Jahrhundert jemanden, der den Kampf gegen den allgegenwärtigen Geist Schleiermachers nicht auf die leichte Schulter nahm." (Herrmann [Anm. 5], 146).

26 SR (Anm. 4), 62f.

27 Über Weiß vgl. Paul Glaue, Art. Weiß, Hermann, in: RGG1 5 (1913), 1875. Der von Ritschl hier inkriminierte Artikel war unter dem Titel Über das Wesen des persönlichen Christenstandes 1881 in den ThStKr erschienen (377-417).

28 Theologie und Metaphysik. Zur Verständigung und Abwehr, Bonn (Marcus) 21887, 55 (Hervorhebung im Text von mir). Im Folgenden als ThuM zitiert.

29 ThuM (Anm. 28), 54. Diese Art des Umgangs mit dem Phänomen ,Schleiermacher und Schleiermacherianismus' wird später von Wilhelm Herrmann fast identisch reprodu- 
Zunächst einmal zusammenfassend so viel: In seiner Polemik richtet Ritschl seinen Blick auf Schleiermacher stark von dessen Wirkungsgeschichte her. Von dieser ausgehend übt er an Schleiermacher scharfe Kritik, da dieser für einen Großteil der aus Ritschls Sicht ungesunden Entwicklungen in der evangelischen Kirche und Theologie der ersten Hälfte des 19. Jahrhunderts verantwortlich sein soll. Diese Kritik ist besonders intensiv an die Adresse der so genannten Vermittlungstheologen gerichtet. Deren Anspruch Schleiermachers Erbe zu bewahren, wird radikal hinterfragt. Durch dieses Verfahren eröffnet sich die Möglichkeit, Schleiermacher selbst aus dieser Kritik partiell auszunehmen.

\section{Differenzierte Zustimmung}

Nimmt man diese These als plausibel an, dann stellt sich jedoch in verschärfter Form die Frage, worin nun genau Ritschls Wertschätzung Schleiermachers und worin seine sachliche Kritik des Berliner Theologen bestand. Erste Hinweise haben die zuletzt angeführten Passagen erbracht. So zollte Ritschl Schleiermacher offenbar Respekt für dessen wissenschaftlich theologische Arbeit, genauer: für deren formale Qualität. Der zitierten Stelle aus Theologie und Metaphysik lassen sich ähnliche Texte zur Seite stellen. Im Schleiermacherbuch gibt Ritschl ein „allgemeines Urtheil über seine [sc. Schleiermachers] wissenschaftliche Verfahrensweise“. Dort heißt es explizit und grundsätzlich:

Schleiermacher ist seit der Reformation der Einzige, welcher den wissenschaftlichen Beweis in der Theologie angewendet hat ${ }^{30}$.

Er schränkt dieses Lob zwar sogleich wieder ein, indem er Schleiermacher vielfacher methodischer Fehler in seinen Beweisverfahren zeiht. Dennoch scheint klar, dass es nur wenige Theologen aller Zeiten gab, denen Ritschl überhaupt so viel an Anerkennung bereit war zuzugestehen ${ }^{31}$.

Das ist jedoch nicht alles. Über diese formale Wertschätzung hinaus gibt es - wie die angeführten Texte aus Rechtfertigung und Versöhnung III gezeigt haben - durchaus eine sachlich-theologische Anerkennung. Ritschl schreibt Schleiermacher eine fundamentale Bedeutung als Philosoph, genauer als Ethiker zu. Die sich daraus ergebenden Konsequenzen für seine eigene Theologie sieht er selbst als grundlegend an.

ziert: vgl. Herrmann, Dogmatik (Anm. 14), 141-148, 153-157; vgl.: ebd, 158: „Das Beste bei Schleiermacher hat auf seine Zeit nicht stark gewirkt und ist noch jetzt wenig wirksam."

30 SR (Anm. 4), 18

31 Vgl. SR (Anm. 4), 20: Schleiermacher sei zusammen mit Thomas von Aquin (!) der Einzige, bei dem man „methodische Anleitung zum theologischen Denken“ bekommen könne. 
Diese noch näher zu entfaltende Einschätzung Ritschls wird sich bei genauerer Betrachtung bestätigen. Tatsächlich konvergieren beide Theologien in dieser Hinsicht in erstaunlichem Maße. Dass diese grundsätzliche Verwandtschaft regelmäßige Kritik im Einzelnen nicht verhindert, erklärt sich aus einer freilich ebenfalls fundamentalen Korrektur, die Ritschl an Schleiermachers Konzept vornimmt. Zunächst jedoch zum Gemeinsamen.

Um meine These zu verdeutlichen und zu begründen, gehe ich von Rechtfertigung und Versöhnung aus und dort vom Schleiermacherkapitel des ersten Bandes ${ }^{32}$. Zwar lehnt Ritschl hier (wie bereits erwähnt) Schleiermachers Einordnung als Epochengründer ab. Schleiermacher sei nicht „vorbildlich“, also schulbildend geworden, da seine Neuerungen keine Nachfolger gefunden hätten. Er könne aber mit Recht als „Gesetzgeber“ der neueren Theologie bezeichnet werden:

Es ist gleichgültig, ob Schleiermacher selbst in allen Zweigen der Theologie gleich Musterhaftes geleistet hat; in jedem Falle spiegeln seine theologischen Schriften seine gesetzgeberische Kraft auch darin ab, wo sie dem Kundigen Aufgaben nicht sowohl lösen als verrathen, oder die Aufgaben soweit lösen, daß die Auffassung der Probleme in neuer Gestalt nöthig wird ${ }^{33}$.

Als den „Kodex seiner [sc. Schleiermachers] theologischen Gesetzgebung “ 34 bezeichnet Ritschl die Kurze Darstellung. Gleichzeitig jedoch urteilt er,

daß Schleiermachers leitende Bedeutung für die Theologie in seiner Gesetzgebung für deren Studium nur deshalb ausgedrückt ist, weil er zugleich einen eigentümlichen Maßstab für das Verständnis der christlichen Religion in Anwendung gebracht hat ${ }^{35}$.

Damit sind wir bei einem entscheidenden Punkt angelangt. Ritschl erkennt Schleiermacher deshalb eine entscheidende Bedeutung in der neueren Theologiegeschichte zu, weil dieser der Theologie die richtige Ausgangsfrage in der Religionsproblematik gestellt habe. Zwar ist Ritschl weit davon entfernt, sich Schleiermachers Religionsbegriff vollständig anzueignen, allein „schon die Stellung derselben [sc. Frage sei] von hervorragender Wichtigkeit“36.

Warum ist das so? Ritschl schreibt, genau wie Schleiermacher, der Theologie als akademischer Disziplin die Aufgabe zu, wissenschaftliche Reflexion über die christliche Religion zu sein. Um das aber leisten zu können, muss sie zunächst danach streben, ihr Objekt, eben die christliche Religion so genau als möglich zu bestimmen. Und dazu dient ihr, wie Ritschl im expliziten Einvernehmen mit Schleiermacher formuliert,

\footnotetext{
32 Das ist auch das Verfahren von Korsch, Glaubensgewißheit (Anm. 5), 16-19.

$33 \mathrm{RuV}^{2}$ (Anm. 19), I, 487.

$4 \mathrm{RuV}^{2},($ Anm. 19)I, 486.

$35 \mathrm{RuV}^{2}$, (Anm. 19)I, 487.

$36 \mathrm{RuV}^{2}$, (Anm. 19)I, 487.
} 
die allgemeine Religionsgeschichte, d.h. der historisch vergleichende Blick auf die konkreten Realisierungen von Religion ${ }^{37}$. Damit ist gleichzeitig klar, dass beide gleichermaßen einen alternativen Weg ablehnen, nämlich den der so genannten natürlichen Religion ${ }^{38}$. Ritschl ist sich bewusst, dass Schleiermacher der erste war, der mit Nachdruck dieses Konzept des Rationalismus zurückwies. In seiner Schleiermacherschrift zitiert er in extenso die „in besonders deutlicher und klarer Sprache“ abgefassten entsprechenden Stellen in den Reden ${ }^{39}$.

Dass sich Ritschl mit dieser Ansicht in Übereinstimmung mit Schleiermacher weiß, ist nicht selbstverständlich. Denn Schleiermacher gebraucht zwar sowohl in den Reden wie in der Glaubenslehre das Element des Religionsvergleichs. Dennoch sieht man gewöhnlich nicht darin das systematische Hauptinteresse seiner Religionsphilosophie. Dieses scheint vielmehr auf der Ebene subjektiven Erlebens zu liegen, wenn Schleiermacher Begriffe wie „Sinn und Geschmak fürs Unendliche“40 oder das Gefühl der schlechthinnigen Abhängigkeit ${ }^{41}$ in den Mittelpunkt seiner Theorie rückt. Ritschls Schleiermacherdeutung ist an diesem Punkt allerdings nicht ohne Vorgänger; er folgt in dieser Interpretation seinem Lehrer Baur, der selbst genau an diesem Punkt das zentrale Anliegen der Schleiermacherschen (wie im Übrigen jeder) „Religionsphilosophie“ gesehen hatte ${ }^{42}$.

Für Ritschl legt sich eine solche, gewissermaßen „objektivistische“ Deutung des Schleiermacherschen Religionsverständnisses jedoch noch aus einem anderen, sachlichen Grund nahe. Das wird deutlich aus der unmittelbaren Fortsetzung der oben zitierten Stelle in Rechtfertigung und Versöhnung I. Ritschl schreibt dort:

37 Ritschl, RuV III ${ }^{1}$ (Anm. 19), 4 ( III ${ }^{3}, 8$ f.); RuV I², 495 mit Hinweis auf $\$ 11$ der Glaubenslehre.

38 Zur Kontroverse um natürliche Theologie im 19. Jh. vgl. die exzellente Darstellung von Hans Joachim Birkner, Natürliche Theologie und Offenbarungstheologie. Ein theologiegeschichtlicher Überblick, in: NZSTh 3 (1961) 279-295 = ders., Schleiermacher-Studien, hg. H. Fischer, Berlin/New York (De Gruyter) 1996, 3-22, hier: 11-17.

39 SR (Anm. 4), 5.

40 Friedrich Schleiermacher, Über die Religion. Reden an die Gebildeten unter ihren Verächtern (1799), [hg. G. Meckenstock, Berlin/New York (De Gruyter) 1999], 53. Die Seitenzahlen sind die der Erstausgabe.

41 Schleiermacher, Der christliche Glaube (1830/31) $\mathbb{4}$, hg. Martin Redeker, Berlin/New York (De Gruyter) 71960 (ND 1999), 23.

42 Vgl. in erster Linie Ferdinand Christian Baur, Die christlichen Gnosis, Tübingen (Osiander) 1835, 633f. und zuvor allgemein 18f. Derselbe Grundgedanke findet sich freilich schon in seiner Symbolik und Mythologie (Stuttgart [Metzler] 1824), wo Baur diese Schleiermachersche Einsicht zu seiner Arbeitsgrundlage macht: vgl. ebd, I vii und 104ff. Es ist vielleicht nicht ganz uninteressant, dass Baur in diesem Kontext selbstverständlich davon ausgeht, Schleiermacher betrachte das Christentum als die „absolute Religion“ (Gnosis, 633). 
Nach hergebrachter Weise wird man nun erwarten, daß ich denselben [sc. Religionsbegriff] in seinem Begriffe von der subjectiven Religion ausgedrückt finde. [...] Allein was ich meine, reicht über das Gebiet der Glaubenslehre hinaus. Nämlich Schleiermacher hat die viel allgemeinere Wahrheit festgestellt, daß das geistige, religiöse, sittliche Leben, dessen individuelle Form er zugleich mit der genauesten Beobachtung festgestellt hat, überhaupt nicht außer der entsprechenden Gemeinschaft gedacht werden kann, und daß in der Wechselwirkung mit ihr das Individuum seine eigenthümliche Entwickelung findet. ${ }^{43}$

Ritschl ist sich der Tatsache wohl bewusst, dass die „hergebrachte“ Interpretation Schleiermachers in eine andere Richtung geht als die von ihm selbst in der Nachfolge Baurs beschrittene (auf letzteren Zusammenhang freilich, vergisst' er hier hinzuweisen). Die Rechtfertigung für seine eigene Lektüre Schleiermachers findet er in einem philosophischen, genauer ethischen Prinzip, von dem er annimmt, das dieses Schleiermachers Denken insgesamt - und insofern auch seiner Theologie - zugrunde gelegen habe. Dieser ethische Grundsatz ist - wie aus Ritschls Worten hervorgeht - Schleiermachers spezifische Individualitätstheorie, die für die Bestimmung des sittlichen Einzelnen den Bezug auf eine Gemeinschaft voraussetzt. Es ist dieser Grundsatz, den Ritschl offenbar anerkennt („allgemeinere Wahrheit“), der aus seiner Sicht letztlich auch die Relevanz von Schleiermachers Gebrauch des Religionsbegriffs erklärt. Denn die Präferenz von historisch-konkreten Religionen gegenüber der so genannten natürlichen Religion ist nur eine speziellere Anwendung der Individualitätstheorie, wie in der Schleiermacherschrift festgestellt wird:

Schleiermacher erklärt, daß die sogenannte natürliche Religion, jener Glaube an Gott und an Unsterblichkeit, welchem die Mehrzahl seiner gebildeten Zeitgenossen anhing, kein ursprüngliches Datum des geistigen Lebens, daß vielmehr die Religion immer nur in den positiven Gestalten der geschichtlichen Religionsgemeinschaften da sei. Diese Wahrnehmung aber hat er aus der Analogie zu seiner allgemeinen Überzeugung gemacht, daß die Menschen ihre Bestimmung in ihrer geistigen Eigentümlichkeit erreichen, indem sie eine Verbindung der allgemeinen Motive des Handelns mit ihren individuellen Anlagen unter den besonderen Bedingungen ihrer persönlichen Bildungsgeschichte vollziehen. ${ }^{44}$

Denselben Gedanken wird man auch in der Darstellung in Rechtfertigung und Versöhnung I substituieren dürfen. Das heißt aber, dass mittels dieser Individualitätstheorie die Überlegenheit einer auf dem Religionsbegriff basierenden Theologie gegenüber der natürlichen Theologie überhaupt erst einsichtig wird. Das hat weiterhin tiefgreifende Folgen für das Verständnis von Religion und den theologischen Umgang mit dieser. Denn zu einem Individuum von Religion gelangt man nicht über ein „Quantum von Stoff“, wie Schleiermacher sagt ${ }^{45}$, sondern nur - so versteht es jeden-

$43 \mathrm{RuV} \mathrm{I}^{2}$ (Anm. 19), $487 \mathrm{f}$.

44 SR (Anm. 4), 4.

45 Schleiermacher, Über die Religion (Anm. 40), 281. 
falls Ritschl - über ihre Weltanschauung, eine „organisirende Grundanschauung", die niemand

im objectiven Bewußtsein hat, ohne sich selbst nach ihr zu beurtheilen und ihr gemäß zu leben ${ }^{46}$.

Grundlegend für die Theologie wird demnach die Aufdeckung einer solchen Grundanschauung im Christentum, die die Selbstbeurteilung und das Handeln der Angehörigen der Kirche strukturiert, und ihre systematische Entfaltung in Glaubens- und Sittenlehre.

Angesichts der Bedeutung, die diesen Weichenstellungen zukommt, lässt sich an dieser Stelle bereits erahnen, dass die sich abzeichnende Konvergenz tatsächlich die religionsphilosophischen Grundlagen betrifft. Es geht jedoch um noch mehr als den Religionsbegriff. Um den relevanten Zusammenhang voll zu erfassen, empfiehlt es sich, an dieser Stelle auf den von Ritschl hauptsächlich herangezogenen Argumentationsgang Schleiermachers zurückzugehen (1). Von dort aus können dann (2) Ritschls Lektüre und deren Konsequenzen rekonstruiert werden.

1. Es muss als Zeichen für Ritschls hermeneutischen Scharfsinn gelten, dass er die fundamentale Bedeutung der Individualitätstheorie vom „individuellen Allgemeinen“ für Schleiermachers Denken insgesamt gesehen hat. Die Bestätigung für dieses Urteil durch Diltheys Publikation der frühesten schriftstellerischen Versuche Schleiermachers kann im Blick auf die erste Auflage von RuV erst nachträglich erfolgt sein. Angesichts dessen ist übrigens bemerkenswert - und Indiz für Ritschls großes Interesse an diesem Sachverhalt -, dass ein Hinweis auf Diltheys Untersuchungen zu dieser Frage von Ritschl offenbar in letzter Minute in das Manuskript von RuV I eingetragen wurde - die beiden Bücher erschienen 1870 im Abstand von nur wenigen Monaten ${ }^{47}$.

Im Rahmen von RuV stellt Ritschl den von ihm gemeinten Zusammenhang im Wesentlichen auf der Grundlage der ersten Akademieabhandlung Über das höchste Gut von 1827 dar. Dort knüpft Schleiermacher an seine voraufgegangene Kritik an der kantischen und fichteschen Pflichten- und Tugendethik an, um zu zeigen, dass der aus der antiken Ethik stammende Begriff des Gutes in der Ethik notwendig sei, um die Sittenlehre „in einen richtiger und gerader auf das Ziel hinführenden Entwicklungsgang “ zu führen ${ }^{48}$. Denn nur dieser Begriff erlaube die Integration dessen was vom sittlichen Handeln hervorgebracht wird und vermeide so die aus Schleiermachers Sicht verhängnisvolle Abkapselung der subjektiven Perspektive des Handelnden von den Produkten seines Handelns.

46 SR (Anm. 4), 11.

47 Vgl. RuV I' (Anm. 19), 477.

48 Friedrich Schleiermacher, Über den Begriff des höchsten Gutes. Erste Abhandlung. SW III/2, 446-468 = KGA I/11, hg. Martin Rössler, 535-553, hier: 544,10f. 
Für Schleiermacher muss freilich ein weiteres Element hinzukommen, das die antike Tradition der Güterethik vernachlässigt hatte: die gemeinschaftliche Dimension des höchsten Gutes. Denn nur dadurch, dass die „Wirksamkeit des einzelnen“ in ihrer Verbundenheit mit der „der andern“ in den Blick kommt ${ }^{49}$, könne den Aporien des Zweckbegriffs in der Ethik begegnet werden, die die Ausscheidung teleologischer Kategorien aus der Ethik scheinbar zwingend gemacht hatten. Dass diese Orientierung auf das Ganze nun aber nicht zu einer Nivellierung der Subjekte führt, resultiert für Schleiermacher aus der organischen Konstitution dieses Ganzen:

Diese [sc. Gesamtwirkung der Vernunft], daß ich mich so ausdrücke, als einen Organismus aufzustellen, in welchem jeder verwirrende Gegensaz von Mittel und Zweck aufgehoben, jedes Auseinander auch ein Ineinander, jeder Theil auch das Ganze ist, nichts aber mit aufgenommen wird, was nicht aus dem Leben der Vernunft im menschlichen Geschlecht entsprungen ist und dasselbe auch fortpflanzt und erneuert, das ist es, was ich mir unter einer Darstellung des höchsten Gutes denke. ${ }^{50}$

Da in diesem, wie Schleiermacher an dieser Stelle weiter ausführt, Tugend- und Pflichtbegriff enthalten sind, resultiert eben die von Ritschl ausdrücklich gelobte Verschränkung von Individuum und Gemeinschaft.

Schleiermachers Ethik des höchsten Gutes ist nun eingetragen in eine evolutionäre Theorie, die - in Anlehnung an Schelling und Steffens ${ }^{51}$ - eine Entwicklung mit den Stadien Gravitation - Vegetation - Animalisation - Humanisation umfasst, von denen jede das vorhergehende Stadium überbietet und dabei gleichzeitig in sich aufnimmt ${ }^{52}$. Das hat zwei hier wichtige Konsequenzen. Zum einen wird so noch einmal die notwendige Gemeinschaftlichkeit sittlichen Handelns bewiesen, da bereits dessen natürliches Fundament, die Fortpflanzung, eine Grundform der Gemeinschaft erfordere, die Familie („das Wort natürlich nur in seinem wesentlichen Inhalt genommen ohne nähere Bestimmung der Form“53). Aus der evolutionären Höchststellung der Menschheit zieht Schleiermacher weiterhin die Konsequenz, dass das Grundprinzip der Gattungen, nämlich sowohl Eines in Vielen wie auch Viele in Einem zu sein, im menschlichen Geschlecht in exemplarischer Vollkommenheit ausgebildet ist. Das ist einerseits die Grundlage von wahrer Individualität, erfordert andererseits aber auch die Idee einer Einheit der Menschheit, vermittelt über die Einheit von Völkern:

49 KGA I/11, 547,16.

50 KGA I/11, 548,5-11.

51 Vgl. Hermann Süßkind, Der Einfluss Schellings auf die Entwicklung von Schleiermachers System, Tübingen (Mohr) 1909 (ND Aalen 1983), 194-208.

52 KGA I/11, 549,7-22; vgl. Über den Unterschied zwischen Naturgesetz und Sittengesetz, KGA I/11, 429-451, hier: 448,18-450,9.

$53 \mathrm{KGA} \mathrm{I/11,} \mathrm{550,15f.}$ 
So dürfen demnach auch die Völker nicht für sich sein; und rein stellt sich die Vernunft in ihrem Leben erst dar, wenn auch diese sich jede der Gemeinschaft aller öffnen. ${ }^{54}$

Zweitens besteht das Verhältnis von Natur und Vernunft hier nicht in einem Gegensatz, sondern die beiden verhalten sich zueinander wie Stufen innerhalb eines kontinuierlichen Entwicklungszusammenhanges. Wenn es also bei Schleiermacher z. B. in Anspielung an Gen. 1, 28 heißt, "das älteste sittliche Bewußtsein der Menschen [habe] sich ausgesprochen in dem Beruf die Erde zu beherrschen" 55 , oder die Wirkung der Vernunft (u.a.) so beschreibt, dass „das innerste Wesen des Geistes jeglichem Sein und Erscheinen nach Maßßgabe seiner Empfänglichkeit eingebildet werde auf das vollkommenste" "56, dann ist dies nicht im Sinn eines Dualismus von Natur und Geist zu verstehen, sondern ist die Konsequenz des skizzierten evolutionären Schemas, in dem das je höhere Prinzip das niedrigere in sich schließt und es so gleichsam selbst auf eine höhere Stufe führt.

Dass diese Überlegungen Konsequenzen für das Verständnis von Religion haben müssen, liegt auf der Hand. In der erwähnten Akademieabhandlung verweist Schleiermacher auf diese freilich nur am Rande. Er bringt jedoch dort seine Meinung zum Ausdruck, dass seine theoretische Konstruktion eines Abschlusses bedarf, der seinerseits den irdischen Menschengeist transzendiert. ${ }^{57}$

Dieser Abschluss findet sich in einer Telosformel, die nun eigentlich das höchste Gut repräsentiert. Schleiermacher gibt ihr eine vierfache Form, gemäß der vierfachen Unterteilung des sittlichen Handelns je nachdem ob es primär individuell oder allgemein-menschlich bzw. rezeptivaneignend (organisierend) oder aktiv-gestaltend (symbolisierend) die Einheit von Geist und Natur bewirkt:

Alles dieses ist Eins und keines ohne das andere; aber je nachdem wir den einen Standpunkt nehmen oder den anderen, erscheint das höchste Gut bald als das goldene Zeitalter in der ungetrübten und allgenügenden Mittheilung des eigenthümlichen Lebens, bald als der ewige Friede in der wohlvertheilten Herrschaft der Völker über die Erde, oder als die Vollständigkeit und Unveränderlichkeit des Wissens in der Gemeinschaft der Sprachen, und als das Himmelreich in der Gemeinschaft des frommen Glaubens, jedes von diesen in seiner Besonderheit dann die anderen in sich schließend und das Ganze darstellend. ${ }^{58}$

Die religiöse Telosformel des Himmelreiches ist hier eine von vier Bestimmungen des höchsten Gutes, diejenige, die sich auf die individuelle („,eigenthümliche“) Einbildung des Geistes in die Natur bezieht. Gemeint

\footnotetext{
54 KGA I/11, 552,6-8.

55 KGA I/11, 549,22-24.

56 KGA I/11, 551,39-41.

57 KGA I/11, 552,12-15.

58 KGA I/11, 552,15-24.
} 
ist, wie Schleiermacher in seiner zweiten Akademieabhandlung unter demselben Titel präzisiert, die verallgemeinernde Äußerung des je Besonderen $^{59}$, d.h. die Darstellung des Eigenen in einer allgemein verständlichen Art und Weise durch das „sittliche und fromme Bewußtsein" 60 - im Unterschied z.B. zum Wissen, bei dem das Gemeinsame symbolisierend dargestellt, zum Ausdruck gebracht wird.

Es kann hier nicht darum gehen, die sich gedanklich anschließende Verbindung zu Schleiermachers philosophischer Ethik mit ihrem vierfachen Handlungsbegriff umfassend darzustellen, zumal diese Zusammenhänge gut bekannt sind ${ }^{61}$. Es ist aber nicht unwichtig zu sehen, dass diese Verbindung von Schleiermacher in der besprochenen Akademieabhandlung nur am Rande gestreift wird. Dass die gesamte Konzeption des höchsten Gutes eigentlich nur von ihrer Einbettung in Schleiermachers ethischen Entwurf her deutlich wird, kann einem Leser dieser Abhandlung durchaus entgehen.

2. Es gibt keinen Hinweis, dass Ritschls Schleiermacherinteresse so weit reichte, dass er die Verankerung der Lehre vom höchsten Gut in dem System der philosophischen Ethik versucht hätte nachzuvollziehen. Für ihn ist, wie bereits gezeigt, die spezifische Individualitätstheorie, die einen eigentlichen Gegensatz zwischen dem Einzelnen und dem Allgemeinen beim Menschen nicht gelten lassen will und deshalb die Ausbildung von Personalität beim Menschen parallel mit der gemeinschaftlichen Verbindung zur Menschheit, das Zentrum der Argumentation: „Die sittlich organisierte Gesammtheit des menschlichen Geschlechts ist also als das alle Güter umfassende sittliche Gut zu denken"62. Daneben dürften freilich auch die folgenden Beobachtungen, die Ritschl an Schleiermachers Text machen konnte, eine Rolle gespielt haben:

a) Die Kulturaufgabe der Menschheit wird so bestimmt, dass die Natur immer vollkommener angeeignet, vergeistigt werden soll.

b) Diese Aufgabe ist demnach auf ein bestimmtes Ziel ausgerichtet, also teleologisch.

c) Weiterhin kann die Aufgabe nicht erfüllt werden ohne eine religiöse Fundierung, da der umfassendste Telosbegriff zwangsläufig transzendent ist. So jedenfalls versteht Ritschl Schleiermachers oben zitierte Aussage über die „überirdische Heimath“ des Geistes. Er interpretiert: „[...] d.h. wenn das Ethos religiös gerichtet und begründet ist, - auf der

59 Schleiermacher, Über den Begriff des höchsten Gutes. Zweite Abhandlung. KGA I/11, 657-677, hier: 674,9-675,21.

60 KGA I/11, 674,18f.

61 Vgl. z.B.: Hans Joachim Birkner, Schleiermachers christliche Sittenlehre im Zusammenhang seines philosophisch-theologischen Systems, Berlin (Töpelmann) 1964, 38-41; Michael Moxter, Güterbegriff und Handlungstheorie. Eine Studie zur Ethik Friedrich Schleiermachers, Kampen (Kok Pharos) 1992.

$62 \mathrm{RuV} \mathrm{I}^{1}$ (Anm. 19), 474. 
christlichen Stufe in dem Gedanken des Gottesreiches. "63 Letztere Bemerkung zeigt, dass Ritschl ohne weiteres das Himmelreich mit dem Reich Gottes in Schleiermachers theologischen Schriften gleichsetzt und dieses (unter Ausblendung der bei Schleiermacher formulierten vierfachen Gestalt) als das höchste Gut identifiziert.

Im Rahmen der Darstellung im ersten Band von Rechtfertigung und Versöhnung untermauert Ritschl seine Interpretation der Akademieabhandlung dadurch, dass er sie in unmittelbaren Zusammenhang rückt mit den einleitenden Paragraphen der Glaubenslehre. Hieraus zieht er an dieser Stelle vor allem $\mathbb{} 11$ heran, wohl wegen der dort anzutreffenden Charakterisierung des Christentums als „der teleologischen Frömmigkeit angehörige monotheistische Glaubensweise "64. Auf diese Weise ergibt sich ihm aus Schleiermachers ethischem Begriff des höchsten Gutes ein zumindest indirektes Argument für die Höchstgeltung des Christentums, in jedem Fall eine enge Konvergenz von Ethik und Theologie.

$$
* * *
$$

Es scheint nun so zu sein, dass genau an der hier bezeichneten Stelle der von Ritschl zu Recht auch selbst so empfundene tiefste Kontakt zwischen seiner und Schleiermachers Theologie besteht. Während Ritschl das Schleiermacherkapitel von Rechtfertigung und Versöhnung ausarbeitet, bezeugt er brieflich (in einem Schreiben vom 19. 12. 1869),

daß ich gerade eine Gedankenreihe von Schleiermacher zu reproduciren hatte, in der ich den Schlüssel für meine ganze Theologie anerkenne 65 .

Diese Einschätzung ist ernst zu nehmen. Das wird deutlich, wenn man sich an dieser Stelle einige Grundlagen von Ritschls Denken vergegenwärtigt ${ }^{66}$. Ich nenne - exkursartig - 10 Punkte:

1. Für Ritschls eigenes Denken ist ein Dualismus von Natur und Geist eine nie angezweifelte Prämisse ${ }^{67}$. Er bildet eine Basis jeglichen menschlichen Empfindens und ist Grundlage aller Religion:

63 Ebd.

64 Schleiermacher, Der christliche Glaube, (Anm. 41), 74. Vgl. auch $\mathbb{S}$ 9, ebd, 59-64 zur Erläuterung der Unterscheidung von „teleologischem“ und „ästhetischem“ Frömmigkeitstyp.

65 O Ritschl, Leben (Anm. 7), II 68.

66 Ich lasse das Problem von dessen Entwicklung und geistesgeschichtlichem Hintergrund hier weitgehend beiseite und verweise stattdessen exemplarisch auf die in dieser Hinsicht immer noch indispensible Arbeit von G. Hök (Anm. 5), dazu jetzt auch: Matthias Neugebauer: Lotze und Ritschl. Reich-Gottes-Theologie zwischen nachidealistischer Philosophie und neuzeitlichem Positivismus, Frankfurt/M. u.a. 2002.

67 Vgl. z.B. RuV III ${ }^{3}$ (Anm. 19), 211. 226; ThuM (Anm. 28), 8f. Vgl. Helga Kuhlmann, Die theologische Ethik Albrecht Ritschls, München (Kaiser) 1992, 133-135. 
Die religiöse Weltanschauung ist in allen ihren Arten darauf gestellt, daß der menschliche Geist sich in irgendeinem Grade von den ihn umgebenden Erscheinungen und auf ihn eindringenden Wirkungen der Natur an Werth unterscheidet ${ }^{68}$.

2. Dieses Empfinden ist nun durchaus problematisch für den Menschen, dessen geistige Selbstbehauptung durch den Einfluss der Natur ständig in Frage gestellt ist. Angesichts dessen ist es die Funktion aller Religion, hier Abhilfe zu schaffen, indem sie sich der Unterstützung einer Macht versichert, die einerseits geistig, andererseits in Kontrolle des Naturzusammenhanges ist:

In aller Religion wird mit Hilfe der erhabenen geistigen Macht, welche der Mensch verehrt, die Lösung des Widerspruches erstrebt, in welchem der Mensch sich vorfindet als Theil der Naturwelt und als geistige Persönlichkeit, welche den Anspruch macht, die Natur zu beherrschen ${ }^{69}$.

3. Aus diesem Verständnis von Religion ergeben sich für Ritschl unmittelbar zwei Konsequenzen: Religion hat notwendig eine kultische Dimension, als deren Kern Ritschl das Opfer betrachtet, und ist daher nur als soziales, dabei praktisches Phänomen richtig zu erfassen. Zweitens, alle Religion beruht auf Offenbarung. Ersteres deutet Ritschl so, dass durch „die Aufopferung von erworbenem Eigenthum“70, die gleichzeitig als „Anstrengung des Willens“ gefasst ist ${ }^{71}$, die Überlegenheit der von der Gottheit verliehenen geistigen Güter über die, „welche dem Menschen naturgemäß oder durch seine Arbeit zustehen" praktisch anerkannt wird $^{72}$. Insofern ist der Kult

die Realisirung des erstrebten Gutes durch die praktische Anerkennung der Macht, von welcher dasselbe verliehen wird ${ }^{73}$.

Da der Kultus aber nicht ohne konkrete und damit in gewissem Sinne kontingente Regeln gedacht werden kann, entsteht das Erfordernis von Offenbarung:

Die Besonderheit des Ortes, an welchem ein Gott seine Verehrung angeordnet hat, die Besonderheit der Zeiten, in welchen die Götter durch das Land ziehen, und zur Feier ihrer Feste auffordern, [...] also die Besonderheit ist das Element, durch welches die Menschen sich angetrieben finden, die verschiedenen Beziehungen der Religion aufzufassen und sie im Cultus praktisch zu verknüpfen ${ }^{74}$.

4. Alle diese Merkmale zusammengenommen machen deutlich, warum für Ritschl die natürliche Religion des Rationalismus, die auf Allgemeinheit statt Besonderheit setzte und Kult und Offenbarung für ephemer

68 ThuM (Anm. 28), 9.

$69 \mathrm{RuV} \mathrm{III}^{3}$ (Anm. 19), 189.

$70 \mathrm{RuV} \mathrm{III}^{3}$ (Anm. 19), 191.

71 SR (Anm. 4), 57.

${ }_{72} \mathrm{RuV} \mathrm{III}^{3}$ (Anm. 19), 191.

$73 \mathrm{RuV} \mathrm{III}^{3}$ (Anm. 19), 192.

$74 \mathrm{RuV} \mathrm{III}^{3}$ (Anm. 19), 193. 
hielt, das genaue Gegenteil von Religion darstellen und deshalb theologisch bedeutungslos sein musste ${ }^{75}$.

5. Wenn also das Christentum als nicht nur die vollkommene, sondern als „die wirkliche Religion selbst“76 erwiesen wird, so durfte diese Aufgabe von ihrer Besonderheit in Kult und Offenbarung - und das hieß primär: von ihrem Stifter, Jesus Christus - gerade nicht absehen ${ }^{77}$. Das bedeutete freilich keine der Tradition gegenüber unkritische Aufgabe. Vielmehr führte Ritschls Religionsverständnis ihn konsequent zu einem Idealbegriff von Religion, der einerseits die besondere Stellung des Christentums erweist, andererseits den Maßstab für seine theologische und praktische Ausgestaltung abgibt. Für Ritschl ist das Christentum insofern die absolute Religion als es durch den Glauben an einen Gott, der Schöpfer und Erhalter der ganzen Welt ist und durch das als Endzweck offenbarte Reich Gottes die Funktion der Religion paradigmatisch erfüllt:

Das Christenthum verbürgt durch seine geschlossene Weltanschauung seinen Gläubigen die Erhaltung zum ewigen [sc. geistigen ${ }^{78}$ ] Leben in dem Reiche Gottes, welches der offenbare Zweck Gottes in der Welt ist, und zwar in dem vollen Sinne, daß der Mensch hiedurch als Ganzes in seiner Art in dem Reiche Gottes über die Welt gestellt wird 79 .

Obgleich Ritschl den Anspruch, das Christentum als absolute Religion zu erweisen, in den späteren Auflagen relativiert hat ${ }^{80}$, hängt doch für ihn der Gebrauch des Religionsbegriffes in der Theologie unlösbar an einer Konstruktion, in der die Stufenfolge der Religionen die theoretische Möglichkeit schafft, dass „diejenige einzelne positive Religion, welche die höchste Stufe einnimmt, zugleich als die ,ganze Religion' erkannt werde" 81 . Denn nur über diese Brücke ist sein Anspruch einzulösen, gleichzeitig Theologie auf dem Standpunkt der Gemeinde zu betreiben ${ }^{82}$ und allgemein wissenschaftlich deren Wahrheit zu beweisen ${ }^{83}$.

6. Entscheidend für unseren Zusammenhang ist der in der Definition gebrauchte Begriff des Zweckes. Ein, wenn nicht der fundamentale

75 Vgl. Rolf Schäfer, Ritschl. Grundlagen eines fast verschollenen dogmatischen Systems, Tübingen (Mohr) 1968, 86-89.

76 Die christliche Vollkommenheit, hg. Cajus Fabricius, Leipzig (Hinrichs) 1924, 9.

77 Das und nur das kann m. E. gemeint sein, wenn Ritschls Theologie gelegentlich als christozentrisch oder als „Offenbarungstheologie“ bezeichnet wird: vgl. Schäfer, Ritschl (Anm. 75), passim, z.B. 88; Weinhardt, Herrmann (Anm. 5), 15. Zutreffend das Urteil von Hök, Theologie (Anm. 5), 49-51.

$78 \mathrm{Vgl}$. RuV III ${ }^{3}$ (Anm. 19), 223: „Die Ewigkeit ist allgemein die Macht des Geistes über die Zeit."

79 RuV III ${ }^{3}$ (Anm. 19), 191.

80 Vgl. RuV III ${ }^{3}$ (Anm. 19), 187f. z. B. mit RuV III' 170.

81 SR (Anm. 4), 7.

$82 \mathrm{RuV} \mathrm{III}^{3}$ (Anm. 19), 2-8.

83 RuV III ${ }^{1}$ (Anm. 19), 14f.; 170. Mit Hök (Theologie [Anm. 5], 331-336) glaube ich, dass Ritschl diese Auffassung prinzipiell beibehalten hat (vgl. auch RuV III ${ }^{3}, 499$ ). 
Unterschied zwischen den Bereichen von Natur und Geist besteht darin, dass (ähnlich wie bei Leibniz ${ }^{84}$ ) der Naturbereich von kausaler Determination beherrscht, der des Geistes jedoch teleologisch strukturiert ist:

Zwar [steht] das Geistesleben, soweit es mit der Natur verflochten ist, unter Gesetzen des Mechanismus [...], aber seine Eigenthümlichkeit gegen die Natur [wird] in praktischen Gesetzen erkannt [...], welche ausdrücken, daß der Geist Zweck an sich ist $\ldots{ }^{85}$

Damit hängt unmittelbar die zentrale Rolle zusammen, die der Begriff des (teleologisch strukturierten) Willens für Ritschls Denken spielt. Dieser ist das eigentliche Signum des Unterschieds des Geistes von der Natur (vgl. oben 1); es ist Kants besondere Leistung, dies herausgestellt zu haben ${ }^{86}$.

7. Die Konsequenzen für die christliche Theologie sind weitreichend. Nur durch eine durchgängig teleologisch, d.h. am Zweckgedanken ausgerichtete Struktur wird sie dem vollendet ethischen Charakter der christlichen Religion gerecht. Ein Großteil von Ritschls polemischen Äußerungen über bestimmte Erscheinungen der Theologiegeschichte wird nur dann verständlich, wenn man sich diese Grundentscheidungen vergegenwärtigt. So ist für Ritschl jede Form von Theologie, die den Gottesbegriff von einem allgemeinen Seinsbegriff her denkt (also jenseits der Trennung in Natur und Geist) „metaphysisch“ und $e o$ ipso inakzeptabel. Entsprechend dem teleologischen Charakter der christlichen Religion muss vielmehr auch beim Gottesbegriff von der Kategorie des Zweckes her gedacht werden. Für Ritschl ist der christliche Gott daher zentral und ausschließlich Wille, genauer der Liebeswille, der durch sein Ziel oder seinen Zweck, eben die Erlösung der Welt, bestimmt ist. 87

84 Vgl. z.B. Gottfried Wilhelm Leibniz, Principes de la Nature et de la Grace, fondés en raison 3. Philosophische Schriften, hg. C.I. Gerhardt, Berlin 1875-1890, 6, 599. Frappierend und historisch wohl näher liegend ist im Übrigen die Parallele zu Adolf Trendelenburgs Logischen Untersuchungen (2 Bd., Berlin [Bethge] 1840). Vgl. z.B. Trendelenburg, II 74-79 und 352-363 und Hök, Theologie (Anm. 5), 27f.; 32-35. Die immer noch unterschätzte Dimension der Wirkung Trendelenburgs auf die nachidealistische Philosophie zeichnet in Umrissen Klaus Christian Köhnke, Entstehung und Aufstieg des Neukantianismus. Die deutsche Universitätsphilosophie zwischen Idealismus und Positivismus, Frankfurt am Main (Suhrkamp) 1986, 23-47 und passim. In diesem Zusammenhang ist dann auch zu beachten, dass Friedrich Überweg in seinem 1857 erschienenen System der Logik und Geschichte der logischen Lehren (Bonn [Marcus] 21865, iv) Trendelenburg ganz nahe an Schleiermacher heranrückt, „wiewohl ohne historische Abhängigkeit von dem letzteren“. Vgl. Köhnke, 58f. Vgl. auch Neugebauer, Lotze (Anm. 66), 111-151, der v.a. auf die Konzeptionen Kants und Lotzes hinweist.

$85 \mathrm{RuV} \mathrm{III}^{3}$ (Anm. 19), 211.

86 RuV I2 (Anm. 19), 430; 434-437; 488.

87 Vgl. RuV III ${ }^{3}$ (Anm. 19), 262-264. 
8. Der biblische und theologische Name für diesen Zielbegriff ist aber nun der des Reiches Gottes, in dem Ritschl den Kern der Botschaft Jesu erkennt. Da dieses Ziel ebenso dasjenige der Welt ist, konvergieren Gott und Welt in der teleologischen bzw. ethischen Perspektive - daher ist für Ritschl jede Form von negativer Theologie („Areopagitismus“) ein Überrest des Platonismus im Christentum, ein Rudiment physischen Denkens $^{88}$. Als Korrespondenzbegriff zum göttlichen Liebeswillen kommt freilich die Welt nur insofern in Betracht als sie geistig und also eine Einheit ist ${ }^{89}$. Deshalb ist das Reich Gottes als Zweck der Welt so bestimmt, dass es durch die geistige Einheit der Menschen auf der Grundlage gemeinsame Ausrichtung des Willens zustande kommt, die ausdrücklich von ihrer natürlichen Gattungseinheit abgehoben wird:

Diese Idee der sittlichen Vereinigung des menschlichen Geschlechtes durch das Handeln aus dem Motiv der allgemeinen Nächstenliebe stellt eine Einheit der Vielen dar, welche dem Gebiet des durchaus bestimmten, nämlich des guten Willens angehört. Die Vielheit der Geister, welche bei ihrer natürlichen gattungsmäßigen Zusammengehörigkeit doch in der Bethätigung ihrer Willenskraft möglichst uneinig sein können, erreicht in dem gegenseitigen und gemeinschaftlichen Handeln aus Liebe, welches keine Schranke mehr an der Familie, dem Stande und der Volksgenossenschaft findet, eine übernatürliche Einheit, ohne daß die gegebene Vielheit dadurch vernichtet würde ${ }^{90}$.

9. Dabei hebt diese Einheit jedoch die individuelle Besonderheit nicht auf, sondern konstituiert sie recht verstanden erst im eigentlichen Sinn. Das ist aus Ritschls Sicht der konzeptionelle Vorteil einer Einigung durch den Zweckgedanken im Unterschied zu einer Verbindung durch ein Gesetz, das das Allgemeine in Antithese zum Besonderen setzt ${ }^{91}$. Die Kritik des abstrakt Allgemeinen zugunsten des historisch Konkreten und Besonderen (vgl. oben 4.) erfährt hier nochmals eine theoretische Unterfütterung.

10. Es ist für Ritschl entscheidend, hier ein Zusammenstimmen von christlicher Theologie und ethischer Theorie zu finden, da auch diese zu einem Telosbegriff, nämlich dem des höchsten Gutes gelangt, das Kant und auch Schleiermacher mit dem Reich Gottes identifizieren. Für Ritschl wird Theologie so zur Wissenschaft, indem sie zeigen kann, dass eine Theorie des Christentums und eine wissenschaftliche Ethik in dem Sinne komplementär sind, dass erstere auf die Ethik gestützt einen wissen-

88 RuV III ${ }^{3}$ (Anm. 19), 257-259; SR (Anm. 4), 34 f.

$89 \mathrm{RuV} \mathrm{III}^{3}$ (Anm. 19), 265, vgl. ebd.: „Denn die Materie ist der ursprüngliche Ausdruck des Vielen.“

$90 \mathrm{RuV} \mathrm{III}{ }^{3}$ (Anm. 19), 267.

91 SR (Anm. 4), 35. Vgl. wiederum Trendelenburg, Untersuchungen (Anm. 84), II 76: „So löst sich das alte Problem der Einheit in der Vielheit auf dem Gebiete des Zweckes durch den Gedanken selbst, und die organische Einheit ist seine höchste Darstellung. “ Dort folgt dann die Entfaltung der auch bei Ritschl vorausgesetzten organisch gegliederten Struktur dieses Ganzen (ebd, 77f.). 
schaftlichen Beweis für die Wahrheit der christlichen Religion führen kann, während umgekehrt die Ethik anerkennen muss, dass für das von ihr postulierte Ziel der christliche Glaube als, Weltanschauung' vorausgesetzt werden muss, da dieser Glauben auf Begriffen ruht, die gewissermaßen pragmatische Voraussetzungen für moralisches Handeln darstel$\operatorname{len}^{92}$.

$$
* * *
$$

Erst aus diesen Zusammenhängen wird, so meine ich, Ritschls brieflich geäußerte enthusiastische Einschätzung verständlich. Denn diese, auch untereinander eng verbundenen Grundentscheidungen der Ritschlschen Theologie verdeutlichen, in welchem Maß die hinsichtlich der Individualitätstheorie und der damit unmittelbar verbundenen $\mathrm{Zu}$ wendung einerseits zum „Besonderen“ (der historischen Religion, der Offenbarung, Christus), andererseits zu Teleologie und Reich Gottes bestehende Zustimmung Ritschls zu Schleiermacher jene Grundentscheidungen bestimmen ${ }^{93}$. Dabei ist die Beobachtung dieser Gemeinsamkeiten sicher unmittelbar auch von dem Zweifel begleitet, ob denn tatsächlich alles, was da ähnlich klingt und aussieht auch tatsächlich Gemeinsamkeit ist. Darauf ist noch zurückzukommen.

Zusammenfassend hier zunächst in drei Punkten der Kern von Ritschls Akzeptanz Schleiermacherschen Denkens. Ritschl stimmt Schleiermacher pointiert zu insofern dieser

- den theologischen Zentralbegriff des Reiches Gottes identifiziert mit dem Telosbegriff einer Güterethik, eingebettet in eine Dialektik von Natur und Geist und konsequent sozial ausgerichtet;

- gegen die natürliche Religion des Rationalismus den Blick auf historisch-konkrete Religionen richtet und das Christentum als eine solche - und zwar im Prinzip als die absolute - ansieht und theologisch entsprechend thematisiert;

- beides begründet und zusammenhält durch eine Individualitätstheorie, die im geistigen Bereich das Einzelne und das Allgemeine nicht als Widersprüche sieht.

Dass dies die Antwort auf die Frage ist, inwiefern Ritschl Schleiermacher als wegweisend für die Theologie ansah, wird auch deutlich, wenn wir uns an dieser Stelle nochmals an die oben (bei Anm. $23 \mathrm{f}$.) zitierten Passagen aus dem Anfang des dritten Bandes von RuV erinnern. Im Vergleich zeigt sich nun, dass es diesen komprimierten Formulierungen darum ging, genau diese Intention auszudrücken.

92 RuV III ${ }^{1}$ (Anm. 19), 12-15; III³ , 499. Vgl. oben Anm. 83.

93 Im Grundsatz kommt zum selben Ergebnis: Chr. Nottmeier, Harnack (Anm. 6), 69-73. 


\section{Die Kritik}

Die Reverenz, die Ritschl Schleiermacher gelegentlich erweist, hindert ihn jedoch nicht daran, die Ausführung von dessen Theologie in den Reden und der Glaubenslehre scharf zu kritisieren. Es kann im Folgenden nicht darum gehen, alle Einzelvorwürfe, die Ritschl Schleiermacher in den einschlägigen Zusammenhängen macht, zu bedenken. Zahlreiche dieser Kritikpunkte beruhen auf vermeintlich inkonsequenter Gedankenführung Schleiermachers. Vielmehr kommt es auf das Grundlegende an. Dazu ergeben sich zwei Fragen: Erstens, wie äußert Ritschl selbst seine Einwände gegen Schleiermacher und welche systematischen $\mathrm{Zu}$ sammenhänge bestehen zwischen den einzelnen Monita? Zweitens, wie stellt sich die Sache aus der Außenperspektive dar? Gibt es tatsächlich fundamentale Unterschiede zwischen den beiden Theologen und, wenn ja, worin bestehen sie und wie verhalten sie sich zu den erkannten Gemeinsamkeiten? Eine Antwort auf letztere Frage wird diese Untersuchung insofern zum Abschluss bringen, als sich durch sie die hier zu vertretende Deutung des theologischen Verhältnisses der beiden Theologen ergeben wird.

a) Die von Ritschl gebrauchten Schlagworte zur Kritik der Schleiermacherschen Theologie sind gut bekannt. Jedoch, wie schon im Fall seiner positiven Voten lohnt es sich auch hier, genauer hinzusehen, um deren Bedeutung zu eruieren. Ich systematisiere 6 Punkte:

1. Ritschl kritisiert, Schleiermacher habe es versäumt, sich Kants spezifisches, nichtnatürliches Verständnis des Willens anzueignen und ist dadurch - so wird man folgern dürfen - der kategorialen Scheidung von Natur und Geist letztlich nicht gerecht geworden ${ }^{94}$. Dieses Versäumnis schlägt sich in seiner Religionstheorie insofern nieder als dort die Relevanz des Kults, der durch Willensanstrengung zustande kommt, unterschätzt bzw. vernachlässigt wird ${ }^{95}$.

2. Unmittelbar damit hängt der Vorwurf zusammen, Schleiermacher habe den teleologischen Charakter des Christentums nicht genügend herausgestellt ${ }^{96}$. So habe er in seiner Theologie regelmäßig die Interaktion geistiger Größen nach dem Kausalgesetz und im quantitativen Schema gedeutet ${ }^{97}$. Auf diese Weise sei seine richtige Einsicht von der zentralen Bedeutung des Reiches Gottes für die Theologie in der Durchführung nicht ausreichend zum Zuge gekommen.

$94 \mathrm{RuV} \mathrm{I}^{1}$ (Anm. 19), $469 \mathrm{f}$.

95 Vgl. SR (Anm. 4), 56f.

$96 \mathrm{RuV} \mathrm{III}^{3}$ (Anm. 19), 9.

$97 \mathrm{RuVI}^{1}$ (Anm. 19), $469 \mathrm{f}$. 
3. Im selben Zusammenhang ist wohl auch die Kritik an Schleiermachers „abstraktem Monotheismus“ zu sehen"8, womit wohl dessen Verständnis von Gott als „Indifferenz aller Gegensätze“99 gemeint ist. Das ist eben der von Ritschl abgelehnte Gottesbegriff des „Areopagitismus“ und nicht der dem Christentum angemessene teleologische. Dieses grundsätzliche Versäumnis ist für Ritschl der eigentliche Grund für Schleiermachers ,Pantheismus ' - wie man weiß ein gängiges Monitum in der Schleiermacherkritik des 19. Jahrhunderts ${ }^{100}$.

4. Als wichtige Ursache für diese theologischen Versäumnisse nennt Ritschl Schleiermachers Vernachlässigung des AT, das in gerade diesen Punkten die Vorbereitung der von Jesus gestifteten Religion enthalte ${ }^{101}$.

5. Auch Schleiermachers Ausgestaltung des Religionsbegriffs wird von Ritschl kritisiert. Die in der Glaubenslehre gebotene Formel vom „Gefühl der schlechthinnigen Abhängigkeit“ sei „,indifferent"102 bzw. „neutral“"103. Schleiermacher habe nämlich Religion zwar gelegentlich als einen Idealbegriff, oft aber auch schlicht als Gattungsbegriff behandelt. Nur im ersten Fall aber gelange man tatsächlich zu individuellen, historischen Religionen, während der allgemeine Religionsbegriff faktisch einen Rückfall in die abgelehnte natürliche Religion bedeute ${ }^{104}$.

6. Abgesehen von dieser formalen Kritik an Schleiermachers Umgang mit dem Religionsbegriff tadelt Ritschl auch dessen inhaltliche Fixierung als einseitig. In seiner Analyse der Reden versucht er zu zeigen, dass der allgemeine Religionsbegriff der zweiten Rede als „Abart des Kunstsinnes“ verstanden werden müsse ${ }^{105}$. Dabei fehle aber die sittliche Dimension der Willensbestimmung, die in allen Religionen den Kult erst ermöglicht ${ }^{106}$. Diese Einseitigkeit führe zu unausgeglichenen Spannungen zwischen einem in Analogie zur griechischen Kosmosfrömmigkeit gebildeten Weltbegriff, zu dem sich das Individuum rein negativ verhalte und der ethischen Individualitätstheorie, da

$98 \mathrm{RuV} \mathrm{III}^{3}$ (Anm. 19), 9.

$99 \mathrm{RuV} \mathrm{I}^{1}$ (Anm. 19), 480.

100 SR (Anm. 4), 31-33. Jener häresiologischen Kritik steht Ritschl freilich ablehnend oder jedenfalls distanziert gegenüber: vgl. SR, 33.58 .

$101 \mathrm{RuV} \mathrm{III}^{3}$ (Anm. 19), 10.

$102 \operatorname{RuV~I}^{1}$ (Anm. 19), 480.

$103 \mathrm{RuV} \mathrm{III}^{3}$ (Anm. 19), 9.

104 SR (Anm. 4), 5-8.

105 SR (Anm. 4), 28. Vgl. dazu auch v. Scheliha, Deutung (Anm. 5), 737-739.

106 SR (Anm. 4), 57. 
zwischen seinem [sc. Schleiermachers] Interesse an dem Werthe der persönlichen, sittlichen Eigenthümlichkeit und seinem pantheistischen Schema der Weltanschauung keine Übereinstimmung stattfindet ${ }^{107}$.

Überblickt man diese Aussagen, die die substantiellen Kritikpunkte Ritschls an Schleiermacher enthalten, dann wird in vielen Fällen deren systematischer Zusammenhang unmittelbar deutlich. Ritschl, so meine ich, kritisiert grundlegend dreierlei:

- Schleiermachers Reich-Gottes-Lehre: Das hängt engstens mit der Kritik an Schleiermachers Durchführung von Teleologie und dessen Vernachlässigung des AT zusammen ( 2 und 4), aber auch die Kritik am Gottesbegriff (3) und letztlich auch die an der ,ästhetischen' Religion (5) stehen unmittelbar mit diesem Grundpfeiler der Theologie in Verbindung.

- Seinen Religionsbegriff: Das ist am deutlichsten in den zwei letzten, dabei untereinander eng verbundenen Punkten, spielt freilich zumindest auch im Zusammenhang mit der Teleologie (2) eine Rolle.

- Seine mangelhafte Unterscheidung von Natur und Geist: Dies ist unmittelbar enthalten in seiner Kritik an Schleiermachers Willensbegriff und dem Hinweis auf Kant (1). Der Punkt lässt sich auch so formulieren, dass Schleiermachers Theologie das ethische Moment am Christentum deshalb vernachlässige, weil sie Kants scharfe Trennung von Natur und Sittlichkeit nicht übernommen habe. Es handelt sich hier um den eigentlich grundlegenden Einwand, der letztlich alle anderen begründet, stützt und in einen systematischen Zusammenhalt bringt. Ganz offensichtlich steht dieser Einwand im Hintergrund der Kritik an Schleiermachers unvollständigem Gebrauch des Zweckbegriffs und erklärt diesen (2). Damit hängt aber die gesamte Kritik an Schleiermachers Inkonsequenz hinsichtlich des Reiches Gottes, des Gottesbegriffs (3), des Praktischen in der Religion (6) letztlich ebenfalls daran. Auch die Kritik an der unvollständigen Anwendung des Idealbegriffs auf die Religion (5) ist über den Zusammenhang mit Ethik und Teleologie mittelbar eine Auswirkung dieser Grundkritik.

Diese Struktur ist nun interessanterweise derjenigen analog, die sich am Ende des vorigen Abschnitts hinsichtlich der Anerkennung Schleiermachers durch Ritschl ergeben hatte. Wie dort gezeigt wurde, dass für Ritschl die Individualitätstheorie Schleiermachers letztlich seiner Reich-Gottes-Lehre und seinem Religionsbegriff zugrunde liegt und die Wurzel seiner Anerkennung des Berliner Theologen ist, so erweist sich jetzt die Kritik am Fehlen einer strikten Abgrenzung des Geistes von der Natur als Wurzel der Kritik an Schleiermachers Reich-Gottes- und

107 SR (Anm. 4), $37 \mathrm{f}$. 
Religionsbegriff. Das deutet darauf hin, dass im Letzten diese beiden Theoreme miteinander in Verbindung gebracht werden müssen, um zu einem angemessenen Verständnis der Sicht Ritschls auf Schleiermacher zu gelangen.

Das bedeutet konkret: In der von Ritschl als fundamental gewürdigten Individualitätstheorie Schleiermachers sieht er insofern einen grundsätzlichen Mangel, als diese nicht mit dem von Kant vorgegebenen klaren Dualismus von Natur und Geist verbunden worden sei. Dieses fehlende Moment verhindere effektiv das Wirksamwerden jener Theorie in Schleiermachers Religionsphilosophie und Theologie.

b) Wie stellt sich diese Kritik aus der Distanz dar? Betrifft sie tatsächlich grundsätzliche Unterschiede zwischen den beiden Theologen? Immer wieder ist gemeint worden, Ritschl habe Schleiermacher absichtlich oder unabsichtlich falsch verstanden. So urteilte schon Ritschls Schwiegersohn Johannes Weiss, Ritschls und Schleiermachers Theologien unterschieden sich in ihrer teleologischen Orientierung auf das Reich Gottes nicht grundsätzlich. Weiss bezieht sich vor allem auf $\$ 9$ der Glaubenslehre Schleiermachers, den er so kommentiert:

Schleiermacher gebraucht hier, wie aus all diesen Sätzen hervorgeht, und wie er zum Überfluß selbst erklärt, das Wort „teleologisch“ in einem anderen Sinne als es gewöhnlich gebraucht wird; es soll hier nur bedeuten, „daß die vorherrschende Beziehung auf die sittliche Aufgabe den Grundtypus der frommen Gemütszustände bildet." 108

Insofern bestehe Ritschls Kritik zu Unrecht:

In diesem Zusammenhang erscheint eben das Reich Gottes gar nicht als der göttliche Endzweck, sondern nur als das Ziel menschlichen Handelns. [...] Schleiermacher will hier nichts weiter, als den besonderen religiösen und den sittlichen Charakter der christlichen Frömmigkeit hervorheben ${ }^{109}$.

Eigentlich teleologisch sei die Glaubenslehre dann in $\$ \mathbb{S} 164 \mathrm{ff}$., wo von der Kirche die Rede ist. Es wäre demnach im Wesentlichen Ritschls Missverstehen von Schleiermachers idiosynkratischem Gebrauch des Wortes teleologisch in $\mathbb{S}$ der Glaubenslehre, das den Schein von Widerspruch erzeugt.

Auch Marlin E. Miller sieht den Widerspruch Ritschls gegen Schleiermacher als bedingt durch ein Missverständnis. Ritschl habe seine eigene Vorstellung vom Reich Gottes als einem Endzweck der Geschichte bei Schleiermacher unbesehen vorausgesetzt und vermisse die Konsequenzen, während Schleiermachers Reich Gottes eben im Grundsatz anders konzipiert sei:

108 Johannes Weiß, Die Idee des Reiches Gottes in der Theologie, Gießen (Töpelmann) 1901, 99.

109 Weiß, Idee (Anm. 108), $99 \mathrm{f}$. 
Schleiermacher sieht aber das Problem auf genau umgekehrte Weise und fragt in seiner Theologie nach dem Begründungszusammenhang im Sinne des Ursprungs und Anfangs des Reiches Gottes als einer Gesamtheit sittlicher Zwecke. Deshalb wird die Verbindung von Gott und dem göttlichen Reich einen anderen Ort und eine andere Beziehung zu der menschlichen Geschichte haben als bei Ritschl110.

Schließlich hat auch Eilert Herms in einem instruktiven Aufsatz für ein Missverständnis Ritschls (das dann von Herrmann und Troeltsch wiederholt werde) votiert, das er freilich bereits beim Wirklichkeitsverständnis ansetzt:

Alle genannten Autoren [sc. Ritschl, Herrmann, Troeltsch] versuchen, sich Schleiermacher in einem kantianischen Rahmen klar und verständlich zu machen. Das aber heißt: Alle diese Autoren übersehen, daß re vera in Schleiermachers Religionsverständnis selber ein Daseinsverständnis zur Sprache kommt, welches seinerseits aus einer dezidierten [...] Kritik an eben jenem Verständnis von Wirklichkeit resultiert, das Kants kritischer Philosophie zugrunde liegt ${ }^{111}$.

Weiß und Miller konzentrieren sich auf Ritschls Einwände gegen Schleiermachers Gebrauch des Reiches Gottes, besonders in $\mathbb{9}$ der Glaubenslehre. Ihrem Einwand, Ritschls Kritik sei nur berechtigt, wenn man bereits das Ritschlsche Verständnis von Reich Gottes teilt, ist insofern verständlich, als Ritschl sich gelegentlich so ausdrückt, als habe Schleiermacher von seinen eigenen Voraussetzungen eigentlich zu seiner, Ritschls, Theologie gelangen müssen. Gleichzeitig hat es die hier vorgelegte Analyse zumindest wahrscheinlich gemacht, dass Ritschl sich selbst dessen bewusst war, dass Differenzen im Verständnis des Reiches Gottes zwischen ihm und Schleiermacher in anderen und fundamentaleren Entscheidungen ihren Grund haben.

Angesichts dessen ist es das Verdienst des Beitrages von Eilert Herms, präzise auf die letztlich zu Grunde liegende Unterscheidung der beiden hingewiesen zu haben: Es geht um das Wirklichkeitsverständnis und es geht um den Einfluss Kants ${ }^{112}$; die von Weiss und Miller angeführten Unterschiede im Verständnis von Teleologie und Reich Gottes lassen sich (wie oben bereits dargelegt) darauf zurückführen. Dennoch oder gerade deswegen lässt sich jedoch, wie mir scheint, hier die These begründen, dass Ritschls Widerspruch gegen Schleiermacher im Grundsatz nicht aus einem Missverständnis herrührt, sondern dass er im Gegenteil Gemeinsamkeiten wie Unterschiede recht präzise wahrnimmt und beschreibt.

Es ist oben gezeigt worden, wie fundamental für Ritschls Denken die Antithese von Natur und Geist ist, wie weitgehend dieser Dualismus seine grundlegendsten Weichenstellungen beeinflusst. Sein Verständnis von Re-

110 Marlin E. Miller, Der Übergang. Schleiermachers Theologie des Reiches Gottes im Zusammenhang seines Gesamtdenkens, Gütersloh (Mohn) 1970, 132.

111 Herms, Religion (Anm. 5), 143.

112 Wobei die Frage nach Ritschls Kantverständnis hier dahingestellt sei. 
ligion, von Teleologie, von Ethik etc. beruht letztlich auf dieser Grundentscheidung. Auch für Schleiermachers Ethik ist die Zweiheit von Natur und Vernunft konstitutiv. Bei Schleiermacher gibt jedoch es keinen Dualismus, keine Antithese von Natur und Geist, weil sein Denken insgesamt nicht von kontradiktorischen Prinzipien, sondern von kontinuierlichem Übergang zwischen zwei als Extrem gesetzten Polen beherrscht wird ${ }^{113}$.

Dieser Unterschied hat weitreichende Konsequenzen, nicht zuletzt für das jeweilige Verständnis von Religion und Reich Gottes. Für Schleiermacher ist das entscheidende systematische Problem der Übergang von der durch den einen zu der durch den anderen Pol bestimmten Seite des Kontinuums ${ }^{114}$. An dieser Stelle kommen daher bei ihm Religion und Reich Gottes vor, aber als etwas, was je vorauszusetzen ist und als ein solches nur entdeckt, thematisiert zu werden braucht, um die als Einheit erfahrene Wirklichkeit angemessen zu verstehen. Für Ritschl ist die Zweiheit, die Fremdheit, die Trennung von Natur und Geist die evidente Erfahrung, deren Überwindung dementsprechend die religiöse und sittliche Aufgabe darstellt.

Ohne vorerst über die Berechtigung der einen oder der anderen Positionen zu urteilen, lässt sich dann aber nicht bestreiten, dass Ritschl jedenfalls insofern Recht hat, als er selbst an dieser Stelle den Bruch zwischen seinem eigenen und Schleiermachers Denken diagnostiziert und eine bei Schleiermacher vermeintlich verloren gegangene Einsicht Kants als Beleg dafür anführt. Auch genetisch ist es ja richtig, dass Schleiermachers Weiterarbeit an der von Kant hinterlassenen Ethik mit einer Kritik an dessen Willensbegriff einsetzt ${ }^{115}$.

An diesem Punkt könnte es so scheinen, dass am Ende ein klarer Gegensatz zwischen beiden Theologen stehen bleibt. Dann wäre Ritschls Wahrnehmung der Gemeinsamkeiten oberflächlich, letztlich ein Missverständnis. Und doch hat Ritschl genetisch und systematisch Recht (dies wurde oben bereits konstatiert), wenn er Schleiermachers ethischen Individualitätsbegriff, an den er selbst sich anschließt, für grundlegend in dessen Denken hält. Auch angesichts der grundlegenden Differenzen bleibt es dabei, dass Ritschls gesamte Theologie in ihrer Bestimmtheit durch die Hinwendung zum „Besonderen“ Schleiermachers Impuls verpflichtet bleibt.

113 Vgl. grundsätzlich: Gunter Scholtz, Die Philosophie Schleiermachers, Darmstadt (WBG) $1984,198 \mathrm{ff}$.

114 Miller, Übergang (Anm. 110), passim, bes. 31-36 (mit überzeugendem Verweis auf Platon, Parm. 155 e 3-157 b 5) und $217 \mathrm{ff}$.

115 Vgl. Schleiermachers frühe Abhandlung Über die Freiheit (KGA I/1, 213-356, bes. 226,21-28) und F. Weber, Schleiermachers Wissenschaftsbegriff. Eine Studie aufgrund seiner frühesten Abhandlungen, Gütersloh (Mohn) 1973, 23-36; G. Meckenstock, Deterministische Ethik und kritische Theologie. Die Auseinandersetzung des jungen Schleiermacher mit Kant und Spinoza, Berlin/New York (De Gruyter) 1988, 53-64. 


\section{Fazit}

Es lässt sich somit an dieser Stelle konstatieren, dass Ritschls Äußerungen zu Schleiermacher sowohl eine fundamentale Übereinstimmung wie eine grundsätzliche Abweichung im Wesentlichen präzise beschreiben. Beide wurzeln im selben Grundbereich theologischer bzw. ethischer Orientierung und betreffen dementsprechend weite Bereiche materialer Einzelfragen. Das erklärt die eingangs bemerkte Schwierigkeit, das Verhältnis korrekt zu beschreiben, was zu divergierenden Urteilen in dieser Frage geführt hat.

Es hat sich gezeigt, dass die aus Ritschls Sicht wichtigste Leistung Schleiermachers - seine ethische Individualitätstheorie - unter dem Fehlen einer scharfen Trennung von Natur und Geist leidet. Das hat - im Guten wie im Schlechten - Konsequenzen für das Verständnis von Religion und Reich Gottes und so für praktisch alle theologischen Einzelfragen.

Dieses Ergebnis scheint zunächst aus historischen Gründen bemerkenswert. Ritschls scharfe Analyse, die zeigt, zu welchen Widersprüchen der Versuch führt, Schleiermacher unter dualistischen Vorraussetzungen zu interpretieren, ist im letzten Drittel des 19. Jh. die Ausnahme - während gleichzeitig weitgehend Einigkeit dahin gehend herrschte, Schleiermacher irgendwie mit Kant zu verbinden. Ritschl erweist sich so als scharfsichtiger als mancher seiner Zeitgenossen - erinnert sei an Christoph von Sigwart, der in 1857 erschienenen Aufsätzen Schleiermacher von kantischen Prämissen her zu verstehen versuchte116. Insgesamt scheint die These nahe liegend, Schleiermachers enorme Wirkung im letzten Drittel des 19. und im frühen 20. Jh. fuße nicht zuletzt auf einer mehr oder weniger explizit kantianisierenden Lektüre des Idealisten und Romantikers. Was deren Probleme betrifft, kann ich mich wiederum den Argumenten von Eilert Herms im besagten Aufsatz anschließen.

Das Interesse endet jedoch nicht dort. Ritschls Auseinandersetzung mit Schleiermacher wirft systematische Fragen auf, die auch in der gegenwärtigen theologischen Diskussion, in der Schleiermacher eine kaum geringere Rolle zu spielen scheint als zu Ritschls Zeit, Beachtung verdienen:

1. Zunächst ist dies ganz generell die Frage nach Recht und Relevanz von Ritschls ethischer Schleiermacherlektüre. Auch heute beansprucht der Zusammenhang von Religion und Selbstbewusstsein das größte Interesse theologischer Schleiermacherrezeption. Dagegen findet die Ethik Schleiermachers nach wie vor philosophi-

116 Christoph von Sigwart, Schleiermachers Erkenntnistheorie und ihre Bedeutung für die Grundbegriffe der Glaubenslehre, in: Jahrbücher für Deutsche Theologie 2 (1857), 267-372; Schleiermachers psychologische Voraussetzungen, insbesondere die Begriffe des Gefühls und der Individualität, ebd, 829-864 (ND beider Texte Darmstadt [WBG] 1974). 
sches Interesse und scheint auch da anschlussfähig, wo sie in Gegenwartsdiskursen nicht explizit aufgenommen wird. Angesichts dessen könnte es sich als lohnend erweisen, mit Ritschl nach den theologischen Konsequenzen der Schleiermacherschen Ethik bei ihm selbst oder auch in seinem Sinn über ihn hinaus zu fragen. ${ }^{117}$ Gerade die m.W. kaum berücksichtigte Frage des Willens, die bei Ritschl im Zentrum des Interesses steht, dürfte interessant sein, nicht zuletzt angesichts der Kritik der neueren Philosophie des Geistes an dem - gerade auch von Kant vertretenen - Konzept vom „unbedingt freien Willen“ 118 .

2. Damit unmittelbar verbunden ist die Frage nach dem systematischen Recht beider Positionen. In dem zitierten Aufsatz warnt Eilert Herms vor einer Wiederholung der Fehler der Schleiermacherrezeption des späten 19. Jahrhunderts ${ }^{119}$. Das ist zweifellos berechtigt, wenn es um das richtige Verständnis Schleiermachers geht. Als prinzipiell offen muss hingegen die Frage gelten, inwiefern das von Schleiermacher vorausgesetzte einheitliche Wirklichkeitsverständnis heute die Grundlage theologischer Arbeit bilden kann. Die klaren Alternativen Ritschls könnten den Blick schärfen für Entscheidungen, die so oder so getroffen werden müssen.

3. Schließlich scheinen auch die durch die hier referierte Diskussion um den theologischen Gebrauch des Religionsbegriffs aufgeworfenen Fragen alles andere als überholt. Denn sie zeigt, dass der Enthusiasmus des 19. Jahrhunderts, durch den Gebrauch dieses Begriffs die natürliche Theologie der Aufklärung überwunden zu haben, nur unter der Voraussetzung gerechtfertigt war, dass ein rein generisches Verständnis von Religion als Universalie ausgeschlossen ist. Methodisch wurde dem durch ein letztlich dem Idealismus entlehntes Schema Rechnung getragen, nach dem das Christentum als höchste auch die absolute, also die paradigmatische Religion darstellt, deren theologische Darstellung dementsprechend als repräsentativ für Religion insgesamt gelten durfte. Dieser Zusammenhang erst macht die eigentliche Brisanz von Troeltschs Absolutheitsschrift deutlich. Wenn also die Theologie heute einen allgemeinen Religionsbegriff rezipiert, kehrt sie damit nicht zu Schleiermacher oder dem 19. Jahrhundert, sondern zur natürlichen Theologie der Aufklärung zurück. Sofern aber eine Anknüpfung an erstere beabsichtigt ist, ist zu bedenken, welche

117 Vgl. jetzt: Brent W. Sockness, The Forgotten Moralist: Friedrich Schleiermacher and the Science of Spirit, in: HThR 96 (2003), 317-348.

118 Vgl. jetzt: Peter Bieri, Das Handwerk der Freiheit. Über die Entdeckung des eigenen Willens, Darmstadt (WBG) 2001, 230-279.

119 Herms, Religion (Anm. 5), 165 f. 
neuen Möglichkeiten nach Troeltsch dafür bestehen. Möglicherweise bietet der quasi hermeneutische Ansatz Ritschls in den späteren Auflagen von Rechtfertigung und Versöhnung hierfür Anknüpfungspunkte ${ }^{120}$.

\section{Abstract}

The article considers the relationship between Albrecht Ritschl and Friedrich Schleiermacher. It is argued that beyond the frequent polemics there is both genuine, fundamental agreement and equally fundamental disagreement between the two theologians. Ritschl accepted that Schleiermacher's ethical insight in the specific interaction of individual and community was pivotal for his own theology, while averring that Schleiermacher had failed to share Kant's sharp ontological dualism of nature and spirit. This finding leads to farreaching questions concerning the continuity and discontinuity in $19^{\text {th }}$-century theological development as well as today's theological options in the reception of Schleiermacher.

120 Vgl. wiederum RuV III ${ }^{3}$ (Anm. 19), 184-189. 